\title{
Estagiários em um ambiente escolar: análise político-pedagógica das experimentações vivenciadas
}

\author{
Luiz Eduardo de ALMEIDA'; Marília Nalon PEREIRA'; Vitória Celeste \\ Fernandes Teixeira do CARMO 2,3; Beatriz de Pedro Netto MENDONÇA4; \\ Letícia Ladeira BONATO3,4; Nathália Vianelli MAURÍCIO4; Maria Fernanda \\ Lamim FUHRMANN5; Maria Paula Furtado SEQUET05; Nathan Silva Pena \\ MEDINA ${ }^{5}$; Pedro Elio Rocha CANIATO5; Rayane Norberto TAVARES ${ }^{5}$
}

1 - Docente do Departamento de Odontologia Restauradora, Faculdade de Odontologia, Universidade Federal de Juiz de Fora (UFJF); 2 - Cirurgiã-dentista, Prefeitura Municipal de Juiz de Fora; 3 - Docente do Curso de Odontologia, Faculdade Estácio de Sá de Juiz de Fora; 4 - Odontóloga, Faculdade de Odontologia, Universidade Federal de Juiz de Fora; 5 - Graduando (a) em Odontologia, Faculdade de Odontologia, Universidade Federal de Juiz de Fora (UFJF).

\section{Resumo}

Objetivo: analisar as significâncias político-pedagógicas de vivências experimentadas por estagiários de um curso de Odontologia em um ambiente escolar. Material e Método: Estudo qualitativo transversalmente estruturado sob estratégia narrativo-descritiva e moldado à técnica argumentativa. Resultados: o "Estágio de Clínica Integrada em Atenção Primária" foi didaticamente sistematizado em dois períodos, "Pré-intervenção" e "Intervenção". Do primeiro, se desvendaram duas ações, a "Contextualização dos acadêmicos estagiários" e a "Estruturação, Ambientalização e Levantamento de necessidades do ambiente de trabalho". Já o segundo foi guiado pela lógica pedagógica do instrumento "TPC" (Teorizar-Praticar-Criticar), onde todas as ações programadas seguiram a lógica ativa do planejamento estratégico, ou seja, contextualizadas às realidades do cenário de prática (ambiente escolar). Conclusão: Das experimentações vivenciadas algumas inferências se destacaram: a efetividade do instrumento "TPC" no direcionamento dos acadêmicos estagiários no planejamento estratégico de ações de educação em saúde; o reconhecimento do ambiente escolar como território fértil para o desenvolvimento de atividades promotoras de saúde; a importância de se disseminar, em espaços científicos, os aprendizados advindos de experimentações práticas de estágios.

PALAVRAS-CHAVE: Promoção da saúde. Educação em saúde. Estágio clínico. Relações Comunidade-Instituição. Planejamento estratégico.

\section{AUTOR PARA CORRESPONDÊNCIA}

Luiz Eduardo de Almeida

Departamento de Odontologia Restauradora da Universidade Federal de Juiz de Fora

Rua José Lourenço Kelmer, s/n - CEP: 36036-900 - Campus Universitário - Bairro São Pedro - Juiz de Fora - MG

E-mail: luiz.almeida.ufjf.edu.br@gmail.com 


\section{Introdução}

Em linhas gerais, pode-se afirmar que a consolidação do processo educacional se esbarra na dialética relação entre o pensar e o fazer. Afinal, teoria sem prática se tornaria puro idealismo e abstração, e o contrário se revelaria mero espontaneísmo, pragmatismo ${ }^{1}$.

Refletindo sobre o exposto, pode-se afirmar que práticas educativas que não se esmeram na redução do distanciamento entre o pensar e o fazer se tornam antidialógicas, ou seja, descontextualizadas das condições sociais que a determinam, ou melhor, a justificam.

Sob a mesma lógica, no que tange a reorientação da formação dos profissionais de saúde, a referida interface pensar/fazer se evidencia ${ }^{2,3}$. É deste enlaçamento que se dinamiza um indissociável círculo virtuoso, afinal, são nos cenários práticos (naturalmente extensionistas) que se dão a socialização do resultado de um fato (pesquisa) e/ou de um aprendizado (ensino) ${ }^{4,5}$.

Imbricado ao contexto, os estágios supervisionados emergem como abordagens extramuros fundamentais para o processo formativo dos futuros profissionais de saúde 6 , pois, segundo Bruder et al. ${ }^{7}$ (2017, p. 295):

Os estágios supervisionados são considerados espaços no curso de graduação que permitem integrar o aluno ao contexto social e econômico da região de atuação, nos quais são realizados trabalhos que vão desde a educação em saúde até a reversão dos danos causados pelas doenças ${ }^{7}$.

Contudo, apesar de seus consolidados benefícios, as atividades desenvolvidas nos estágios, pela frequente atribuição genérica que lhe é estabelecida, ainda se conflitam com corriqueiras questões, normalmente atreladas às discussões sobre "onde", "como", e "quando" devem ser realizados ${ }^{8}$.

A partir de então, imbrica-se uma inquietação, a necessidade de se discutir e, principalmente, de se prover um modelo de ensino pautado nas simbióticas relações entre educação (“o pensar”) e 
trabalho ("o fazer"), ou seja, um processo construído na e para realidade, que, segundo Almeida $(2009)^{5}$, uma premissa que se encerra no reconhecimento da prática como fundamento, critério e finalidade da teoria.

Por fim, atravessado pelo exposto, o presente estudo não apenas se justifica, como alicerçou o seu propósito, analisar as significâncias político-pedagógicas experimentadas por estagiários (acadêmicos do "Estágio de Clínica Integrada em Atenção Primária/ECIAP” do curso de Odontologia da Universidade Federal de Juiz de Fora) através do planejamento estratégico de ações educativo-preventivas vivenciadas em um ambiente escolar (pré-escolares da Escola Municipal Santana Itatiaia, Juiz de Fora-MG).

\section{Material e método}

O "Estágio de Clínica Integrada em Atenção Primária/ECIAP" integra, desde 2008, a grade curricular do curso de Odontologia da Universidade Federal de Juiz de Fora (UFJF). Destinado aos acadêmicos do $2^{\circ}$ período, o "ECIAP” conta com 120 horas de carga horária total, sendo 08 semanais. Contempla a matrícula de até 50 acadêmicos estagiários, equitativamente distribuídos em 02 turmas, A (segunda-feira das 14 às 18 h e quarta-feira das 8 às $12 \mathrm{~h}$ ) e B (quarta-feira das 8 às $12 \mathrm{~h}$ e sexta-feira das 14 às $18 \mathrm{~h}$ ).

Indo além, na intenção de prover uma melhor relação tutor-estagiário, cada turma foi dividida em cinco frentes de trabalho (Grupos I-A/B, II I-A/B, III I-A/B, IV I-A/B e V I-A/B). Neste estudo, que integra o processo avaliativo da disciplina, descrevem-se, de forma crítica e reflexiva, as investigações do Grupo IV da Turma B, composta por 05 estagiários.

No que tange ao desenvolvimento de suas ações, de forma a otimizá-las, a lógica do trabalho pedagógico do "ECIAP” foi, e ainda o é, didaticamente sistematizada em dois períodos, "Préintervenção" e “Intervenção" (Figura 1). 


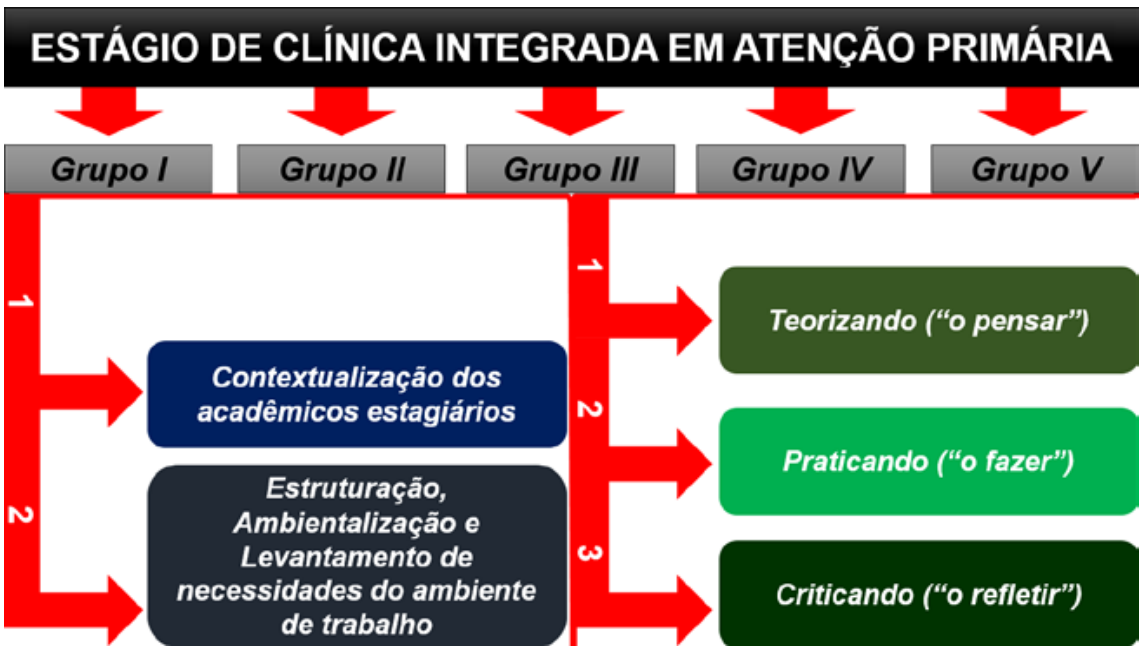

FIGURA 1 · Dinamização do ECIAP

Fonte: Autoria própria (2019)

Nesse contexto, guiado pelos possíveis impactos trazidos pelo ECIAP junto à qualidade da formação acadêmica, o objeto do estudo se delineou na compreensão dos dispositivos político- pedagógicos atrelados às experimentações vivenciadas em um “Ambiente escolar” (Escola Municipal Santana Itatiaia, Juiz de Fora/MG). Para tal, envolveu neste processo analítico a capacitação do graduando em planejar de forma estratégica ações de cunho educativo-preventivas, didaticamente sistematizadas em teorizar e conhecer um território de prática, depois desenvolver e aplicar um plano de ação estratégico e, por fim, avaliar de forma crítica e reflexiva as ações implementadas.

Assim, frente a seus anseios qualitativos, o estudo estruturou-se e se moldou, respectivamente, sob estratégia narrativo-descritiva e técnica argumentativa ${ }^{9-11}$. Por sua transversalidade, serão aqui referendados os acontecimentos vivenciados no ECIAP no primeiro semestre de 2019, mais precisamente entre os meses de março a julho.

Indo além, no tocante aos investigadores, tutores (docentes e odontólogos) e estagiários (acadêmicos graduandos do curso de Odontologia-UFJF), merece destacar a fusão de seus papéis, ora observadores, ora observados. 
Deste percurso foi direcionada a coleta de dados. Essencialmente narrativo-descritiva, foi instrumentalizada pela utilização dos "Relatórios das atividades dos discentes do ECIAP”, materializados sob a construção de portfólios narrativos (relação fazer-aprender: “O que FIZ neste dia?”/“O que APRENDI neste dia”) que frutificaram os registros diários dos estagiários relacionados às experimentações profissionais vivenciadas em seus campo de prática (educação em saúde em ambiente escolar).

Contíguo, seguiu o processo analítico dos fatos. Neste momento, adentraram-se os elementos argumentativos do estudo, embebidos tanto pelas interpretações de seus sujeitos-autores, quanto pelo confronto junto à literatura científica. $O$ que reforçou-se ainda mais o papel ativo dos pesquisadores, aqui, descobridores do significado das ações e das relações por eles vividas e percebidas.

Enfim, calcada no empoderamento de seus elementos empíricos, esta investigação não se baseou em testar hipótese, pelo contrário, galgou-se aqui uma oportunidade de ofertar aos outros leitores um momento de autoanálise, afinal, muitos podem se identificar com determinados aspectos, situações e reflexões.

\section{Resultados e discussão}

Como exposto, figura 1, do primeiro momento do ECIAP, um período de capacitação e contextualização, desvendaram-se duas ações, a "Contextualização dos acadêmicos estagiários" e a "Estruturação, Ambientalização e Levantamento de necessidades do ambiente de trabalho".

Assim, como ponto de partida, coube aos tutores do "ECIAP" promoverem a imersão científica dos discentes estagiários frente aos seus futuros desafios práticos. Ressaltando neste estudo a evidenciação do desenvolvimento de atividades de educação em saúde em um ambiente escolar (Pré-escolares da Escola Municipal Santana Itatiaia, Juiz de Fora/MG). 
Deste ciclo teorizante se desprenderam dois encontros (15/03 e 22/03/2019), sendo neles abordados os seguintes pontos de discussão: 1. Educação em saúde; 2. Educação em saúde em interface com a Odontologia; 3. Educação em saúde no ambiente escolar; 4. Planejamento estratégico para o desenvolvimento de ações de educação em saúde.

Neste ínterim, merecem destaque as técnicas de mediação, que, subsidiadas pelos ideários de diversos estudos ${ }^{12-15}$, se deram por diferentes estratégias problematizadoras de ensino, destacando aulas expositivas, leitura crítica de artigos científicos, grupos de discussão e oficina para construção de materiais didáticos para educação em saúde.

Seguindo, o período "Pré-intervenção" se encerrou com a "Estruturação, Ambientalização e Levantamento de necessidades do ambiente de trabalho".

Referente à "Estruturação”, a Escola Municipal Santana Itatiaia conta com 10 salas, sendo 05 por turno, matutino e vespertino. Assim, buscando cobertura total deste ambiente, cada grupo de trabalho do estágio ficou responsável por uma turma de pré-escolares (sala 04/diurna/19 crianças com idade entre 4 e 5 anos).

Quanto à “Ambientalização”, no dia 27/03/2019 a equipe de estagiários realizou uma visita observacional em seu futuro cenário de trabalho. Desta vistoria buscou-se uma compreensão de como funciona o ambiente escolar, destacando o tamanho da sala de aula, a quantidade e como se agrupam os pré-escolares, seus horários de atividades, onde e de que forma se alimentam, além da avaliação da rotina e da viabilização da higienização bucal das crianças (Figura 2).

A visita do ambiente escolar se encerrou com o "Levantamento de necessidades do ambiente de trabalho". Daqui celebrou-se a pactualização das atividades a serem desenvolvidas na escola. Para tal, didaticamente, a equipe de estagiários se dividiu em duas pontas, uma destinada a entrevistar os professores para 
definirem a temática da ação ("O que vocês gostariam que falássemos?”), e outra a se aproximar das crianças para analisarem os tipos de atividades a serem desenvolvidas ("O que vocês gostam de fazer?"). Dessa sistemática definiram-se a temática e a forma de trabalho, respectivamente, "Medo de dentista/Odontofobia" e lucididade (ensinar de forma divertida).

Até aqui, refletindo um pouco sobre o vivenciado, torna-se fundamental destacar a importância deste momento de escuta, que vai de encontro aos preceitos educacionais de Freire ${ }^{16-18}$ (1983, $2006,2007)$. Segundo o educador, a academia deve romper com o ainda frequente movimento de "via de mão única”, onde tudo é focado aos ensejos paternalistas da universidade, que vai à sociedade levar algo de sua especialidade, logo, se tornando antidialógica e manipuladora ${ }^{16-18}$.

Neste processo, consumado pela quebra da verticalidade, vislumbra-se os moldes da "via de mão dupla". Assim, sustentada na integralidade da vida humana, a academia não apenas leva

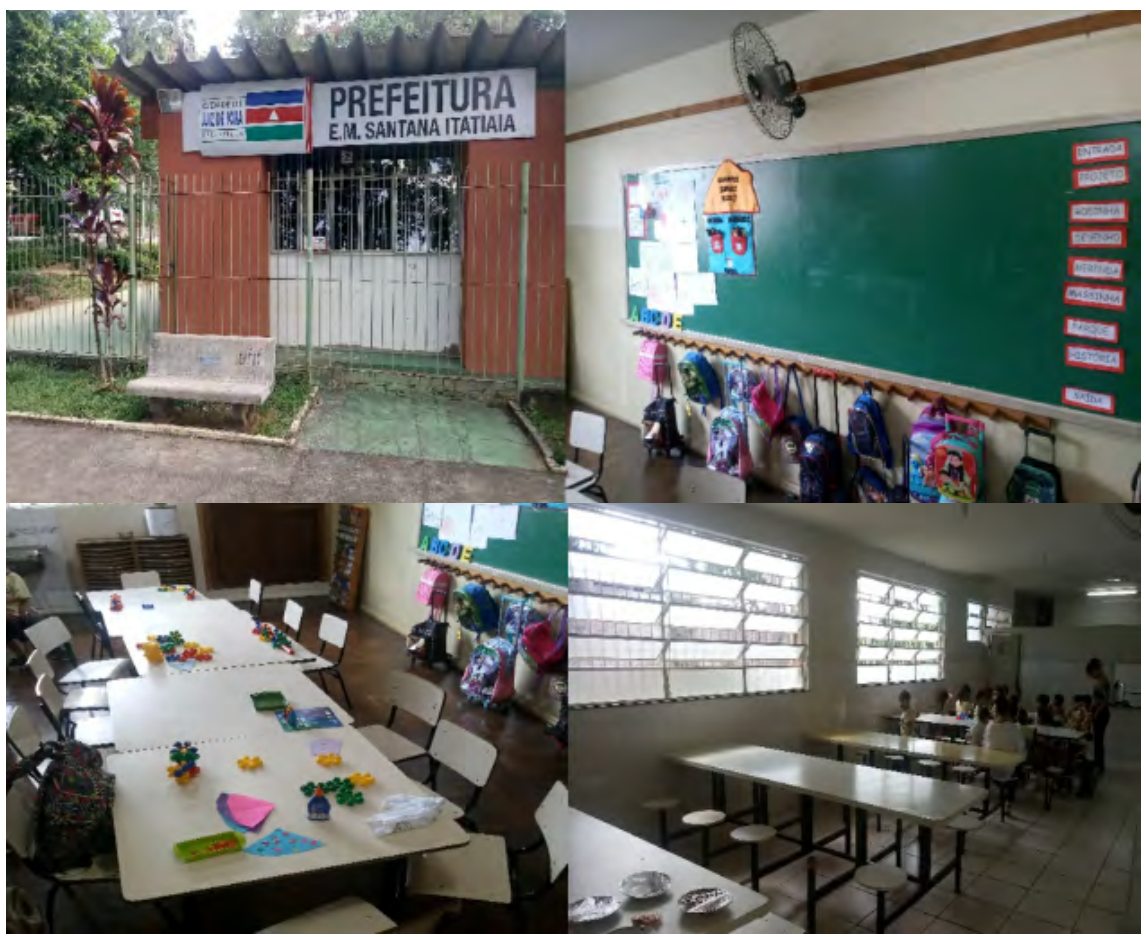

FIGURA 2 · "Ambientalização"

Fonte: Autoria própria (2019) 
informações para a comunidade (ensino), como traz para o cenário universitário vivências (extensão) e dados coletados e interpretados cientificamente (pesquisa).

Contudo, apesar de sua importância, Almeida, Pereira e Oliveira ${ }^{4}$ (2016, p,747) reiteram que este fundamental período de escuta é normalmente burlado pelas ações da academia, consequentemente, "gerando um modelo de trabalhovertical-paternalista, assistencialista e, principalmente, descontextualizado do controle social”.

Encerrada a "Pré-intervenção", abriu-se a "Intervenção". A partir de então, na intenção de se prover um modelo de trabalho que extrapolasse o apenas "fazer", que também alcançasse "o pensar" e o "refletir", o "ECIAP” se via afinado às idealizações dos trabalhos de Almeida, Pereira e Oliveira ${ }^{4}$ (2016) e Almeida, Pereira e $\operatorname{Bara}^{19}$ (2009, p. 746), que materializaram o instrumento “TPC” (Figura 3). Segundo os autores":

O instrumento apresentado [...] se desenvolve em três etapas: Teorizando ("o pensar"), Praticando ("o fazer") e Criticando ("o refletir"), sendo por isso denominado TPC. Sistematicamente, as etapas se complementam, trazendo em seu bojo conceitual a relação entre planejamento estratégico com a eficácia, eficiência e efetividade de ações de educação em saúde ${ }^{4}$.

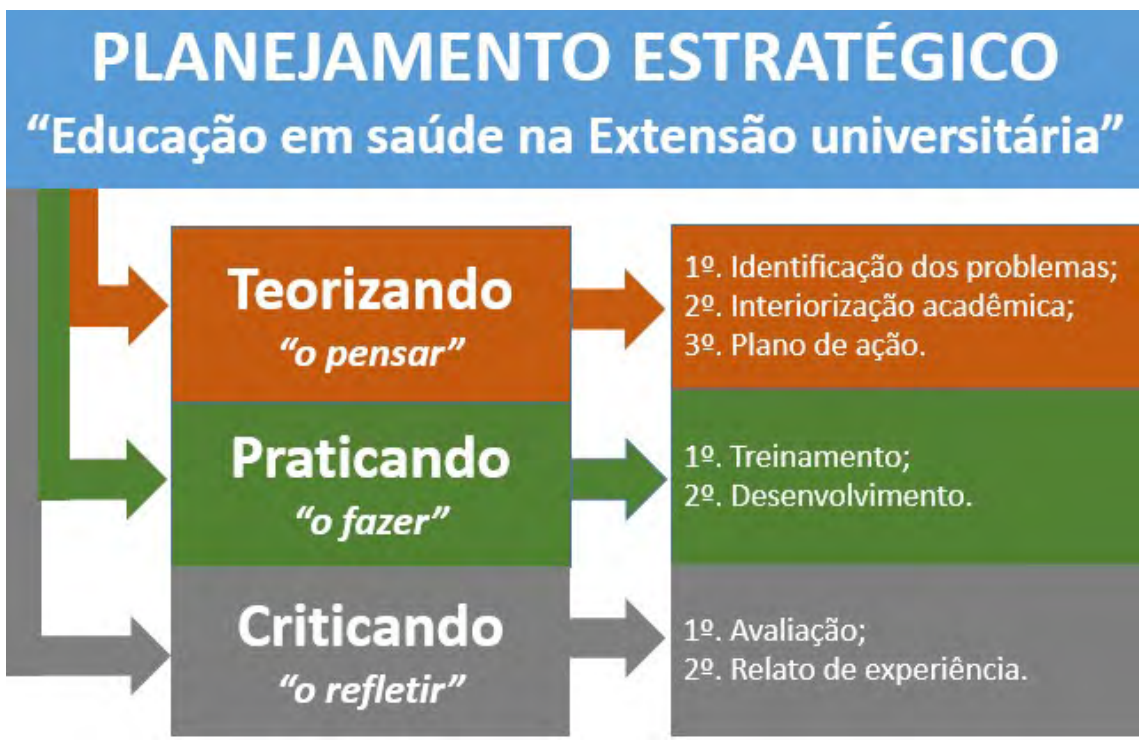

FIGURA $3 \cdot$ Instrumento "TPC"

Fonte: Almeida, Pereira e Oliveira (2016, p.746). 
Aqui, tornam-se mister as considerações de Almeida, Pereira e $\operatorname{Bara}^{19}$ (2009, p. 129). De acordo com os estudiosos ${ }^{19}$, o "TPC", não se consagra como uma "fórmula mágica”, pelo contrário, a ferramenta apenas retrata a rica lógica do "ensinar a fazer contextualizado". Além, conforme os mesmos autores ${ }^{20}$, o verdadeiro intuito do instrumento se efetiva na redução do persistente hiato entre teoria e prática, que, consecutivamente, se choca no necessário e desafiante alinhamento dos tempos de trabalho entre serviço e academia.

Desta forma, a dinamização da ação de educação em saúde no ambiente escolar foi perpassada pela sistematização do "TPC", ou seja, sequenciada em três etapas: "Teorizando/O pensar"; "Praticando/O fazer"; "Criticando/O refletir".

Assim, direcionados pelo instrumento, em 05/04/2019, deu-se o ponto de partida do planejamento estratégico das demandas de trabalho do Grupo IV da Turma B, iniciando-se com a "Identificação do(s) problema(s)".

Neste movimento, apesar da equipe estagiária saber "O quê fazer" (Desenvolver, aos preceitos da ludicidade, uma ação de educação em saúde junto a pré-escolares abordando a temática 'Medo de dentista/Odontofobia'), a mesma se via diante de uma problemática central: "O como fazer?”.

Assim, desafiados pelo questionamento, neste mesmo dia, partiu-se para a "Interiorização acadêmica”. Daqui, foi solicitado aos estagiários o confronto dos ideários teóricos abordados durante a "Contextualização dos acadêmicos estagiários", com os desafios práticos levantados durante o "Levantamento de necessidades do ambiente de trabalho”.

Em outras palavras, os estagiários perceberam o seu real papel como acadêmicos, o de transformar conhecimento científico em instrumento para se mudar uma realidade. 
O encontro foi encerrado com a criação de um "Plano de ação”. Atravessado pelas preconizações da metodologia "Brainstorming”20,21, a dinamização deste período retoma, através da utilização de um questionário direcionador ("O quê?", “Quem?”, “Onde?”, “Quando?”, “Como?”, “Quanto custa?”, “Por quê?" e "Como avaliar?") as orientações propostas pela metodologia do instrumento "TPC" 4,19 .

Após amplo debate e alinhamento de ideias, foi delineado, através da concepção de um mapa conceitual"22,23 (Quadro 1), o "Plano de ação” do Grupo IV da Turma B do “ECIAP”.

Apesar de simples, extraiu-se da etapa de construção "Plano de ação" uma ferramenta indutora no engajamento dos discentes estagiários junto às solutividades de suas demandas. Uma reflexão que embasa o real papel da formação universitária, que não deve se restringir apenas ao fornecimento depositário de conhecimentos para o aluno (aprendizado), pelo contrário, deve aguçar no discente o desejo de aplicá-los (apreensão e carreamento), ou seja, ferramentas transformadoras de uma realidade social.

Além, analisando a lógica educativa utilizada, pode-se afirmar que ela celebra a efetivação do enlace ensino-serviço-comunidade (UFJF-Escola Municipal Santana Itatiaia-Pré-escolares), vista a concepção das atividades planejadas partirem do contexto social ao qual estão inseridas, ou seja, mais importante que os próprios procedimentos didáticos, é ter consciência e conhecimento do "que" e, principalmente, de "quem" serão ensinados.

Encerrado seu estágio observacional (Teorizando/“O pensar”), os estagiários partiram para a etapa "Praticando/O fazer". O ciclo prático se iniciou com o "Treinamento". Neste dia, 12/04/2019, os acadêmicos dinamizaram, junto aos professores/tutores, o “plano de ação” previamente idealizado (Quadro 01), agora, detalhadamente estruturado e materializado. No ensejo, este processo se destacou nos ajustes e alinhamentos finais nas ações a serem desenvolvidas no ambiente escolar. 


\section{"Plano de ação" - Educação em saúde em ambiente escolar - Grupo IV/B}

\section{Questão direcionadora Descrição}

\begin{tabular}{ll} 
“O quê?" & $\begin{array}{l}\text { Desenvolver, aos preceitos da ludicidade, uma ação de educação em saúde junto a } \\
\text { pré-escolares abordando a temática "Medo de dentista/Odontofobia". }\end{array}$ \\
\hline "Quem?" & - Público-alvo: 19 crianças com idade entre 4 e 5 anos; \\
- Executores: 05 estagiários.
\end{tabular}

Para a concepção da ação foram programadas 05 atividades, sendo elas:

\section{Atividade de "Aprendizado"}

- Nome: "Teatro (Não precisamos ter medo do 'Superdentista')";

- Objetivo: Discutir o medo do dentista com os pré-escolares assistidos;

- Dinâmica: a história envolverá quatro personagens, os "Dentinhos Felizes", o "Dentinho Triste" e a "Superdentista". Assim, o narrador da história iniciará a história falando sobre um "Dentinho triste", que por causa da dor e da sujeira ("Bichinho da cárie") não conseguia brincar, estudar e comer. Depois, surgem os "Dentinhos Felizes" dizendo ao amigo doente que ele tem que ir à "Superdentista". Ao ouvir o nome da heroína, o "Dentinho Triste" diz que tem medo. Mais uma vez os dentinhos "Felizes" explicam que a "Superdentista" é a "Doutora dos dentes", ou seja, ela quem cuida da saúde bucal. Assim, os "Dentinhos Felizes" chamam a heroína ("Superdentista", ajudem o nosso amiguinho!). Neste momento as crianças são também estimuladas a pedir auxílio (Gente, vamos todos chamar o "Superdentista"). Assim a personagem surge, limpa o "Dentinho Triste" e o ensina a se cuidar. A partir de então o "Dentinho Triste" se torna saudável e não tem mais medo de dentista.

\section{Atividade de "Apreensão"}

- Nome: "Construindo o 'Superdentista"'.

- Objetivo: Reforçar os conteúdos trabalhados na atividade de aprendizado; - Dinâmica: Aproveitando a personagem "Superdentista", será apresentado às crianças a indumentária do cirurgião-dentista. Os instrumentos serão apresentados de forma lúdica: o jaleco, as luvas, os óculos, a máscara, o gorro, além dos seus instrumentos para combater o maior vilão da boca (o "Bichinho da Cárie"), a escova dental, a pasta de dentes e o fio dental.

\section{Atividade de "Desaceleração das crianças"}

- Nome: "Colorindo os instrumentos de superpoderes do dentista (Escova dental, pasta de dentes e fio dental)";

- Objetivo: desacelerar os pré-escolares para que retomem sua concentração nas atividades de rotina da escola;

- Dinâmica: levar uma folha para colorir. Assim, além reforçar as informações repassadas, deposita-se nesta atividade uma retomada das atividades escolares. 


\section{"Plano de ação" - Educação em saúde em ambiente escolar - Grupo IV/B}

\section{Questão direcionadora Descrição}

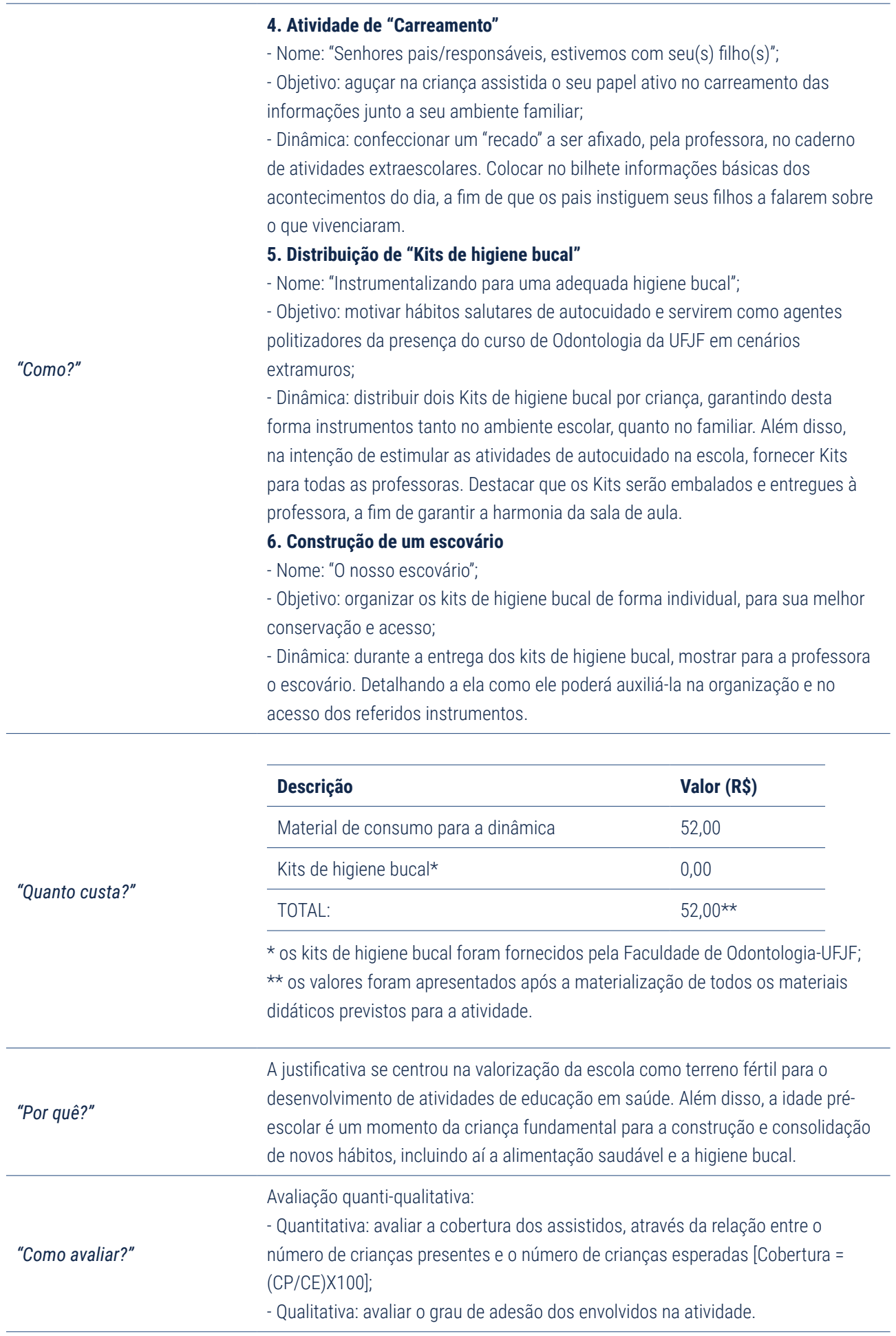

Fonte: Autoria própria (2019). 
Pode-se afirmar que esta etapa teve papel fundamental na preparação da equipe de estagiários. Afinal, ela marca, de forma gradual, a mudança nas funções dos discentes, que se deslocam da condição de observadores/idealizadores para interventores. Almeida e Oliveira Júnior ${ }^{24}(2009$, p.64) ainda complementam, "treinar não é eximir-se do erro, pelo contrário, no treino, através da mimetização de uma realidade, vislumbra-se capacitar uma equipe em prover estratégias secundárias para se contornar os tão frequentes e esperados obstáculos da vida real”.

Assim, previamente treinados, chega o "Desenvolvimento" do plano de ação, em 17/04/2019. Daqui, no tocante às atividades de "Aprendizado" e "Apreensão" (Quadro 1), em linhas gerais, foram efetivas - êxito reconhecido pela ativa participação dos pré-escolares, além da contínua adesão das professoras durante a vivência.

Continuando, na intenção de encerrar as atividades, seguiu-se para a "Desaceleração das crianças”. Assim, foi fornecido para cada criança um desenho temático. Enquanto os infantes coloriam suas artes, gradativamente, se via a retomada das professoras como agentes ativos, ou seja, a rotina escolar.

Tão logo, durante a despedida, foram deixados para os escolares Kits de higiene bucal, além de um escovário para acondicioná-los e otimizar seu acesso. Além disso, na intenção de acessar os familiares dos escolares, foi entregue à professora um bilhete para afixar no caderno de atividades extraescolares (“Carreamento”).

Para encerrar este dia, os professores/tutores se reuniram com os estagiários para se iniciar a "Avaliação” da ação desenvolvida (Criticando/“O pensar”). Para tal, centraram-se nos critérios quanti-qualitativos definidos durante a construção do plano de ação, "Como avaliar”. Daqui extraiu-se uma cobertura de aproximadamente 68,4\% (ausência de 06 crianças), além do alto grau de adesão dos envolvidos durante o desenvolvimento de todas as atividades programadas. 
Adensando um pouco mais, refletindo sobre as experimentações vivenciadas pelo Grupo IV/Turma B, apesar do êxito na execução do plano de ação, ficou evidente o sobrepujamento da realidade prática sobre as expectativas teóricas.

Foi justamente deste confronto entre "teoria/expectativa" e "prática/realidade" que se percebeu o "ECIAP” como agente ativo no processo de aprendizagem dos estagiários. Afinal, os acadêmicos puderam perceber que suas funções extrapolavam o "executar". Deles foram também exigidas outras habilidades, pautadas na plasticidade do "adaptar", do "criar”, do "suprimir", do "postergar", e, principalmente, do "reinventar".

Assim os discentes tiveram a oportunidade de conhecer o maior desafio de um profissional da saúde, o saber lidar com os desafios e, até mesmo, entraves da realidade. Deixando de ver estas situações como alimento para frustrações, pelo contrário, passando a encará-las como uma oportunidade de melhoramento continuado. Percepções que se alicerçam no firmado por Almeida, Pereira e Oliveira ${ }^{4}$ (2016, p.747), "uma equipe aprende com os acertos e se transforma com os erros”.

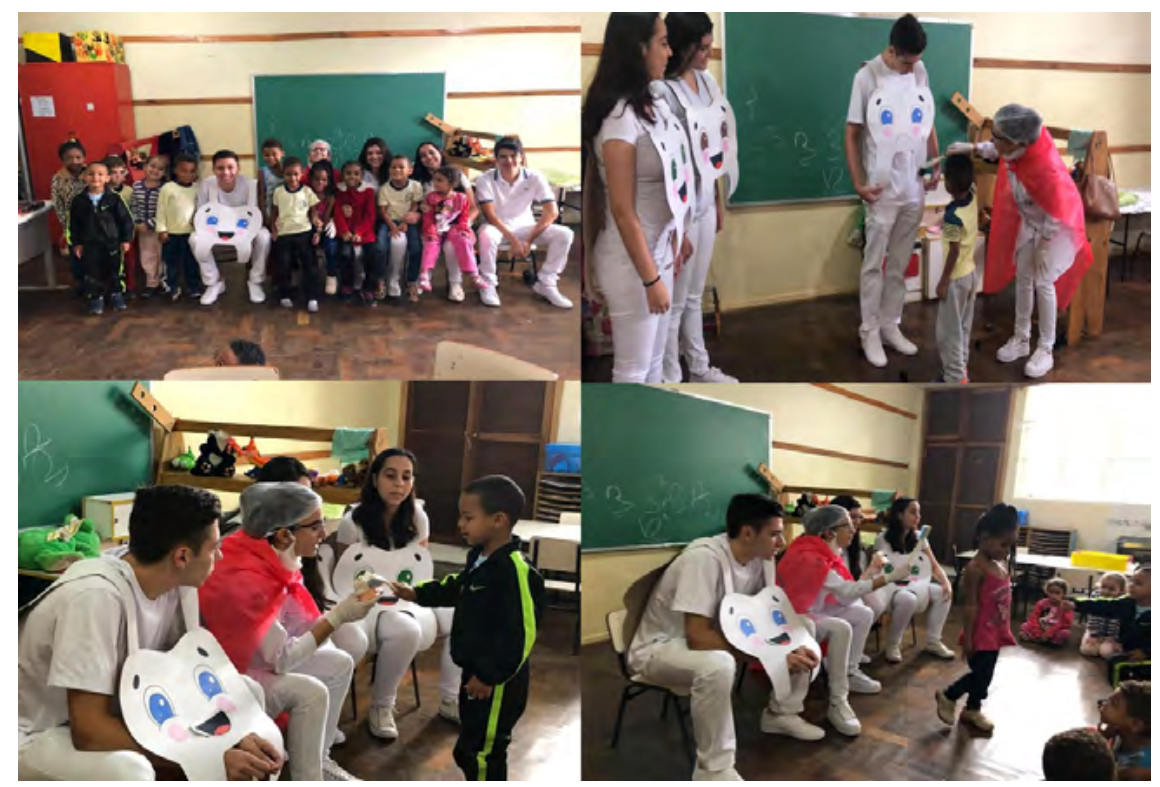

FIgURA 4 - Dinamização do "Plano de ação"

Fonte: Autoria própria (2019). 
Indo além, engendra-se que a teoria não se torna diminuta diante da realidade, pelo contrário, ela ganha forma, sentido, em suma, se justifica. Neste prisma, como dito por Rossetti ${ }^{25}$ (1999, p.77), "Não se deve adaptar os pacientes à ciência, deve-se adaptar a ciência às pessoas”. Complementando, o mesmo autor 25 (1999, p.27), “Aos doutores, ensiná-los a pensar, não aplicar técnicas ou receitas”.

É óbvio que não se poderia esperar, pelo menos em totalidade, a compreensão dos graduandos estagiários das reflexões supradescritas. Por isso a terceira e última etapa do "TPC", "Criticando/O refletir", se fundamentou.

Como previsto, o percurso de reflexão se iniciou com a "Avaliação" e se encerrou com a construção do "Relato de Experiência", que integra o processo avaliativo do "ECIAP". De acordo com Almeida, Pereira e Oliveira ${ }^{4}(2016$, p.747):

Entre as diversas metodologias, destaca-se o "relato de experiência”, ressaltando que sua construção não deve ser direcionada apenas aos acertos, ou seja, deve-se oferecer espaço também para discutir erros e fragilidades ${ }^{4}$.

Assim, reconhecendo o papel de divulgação e troca da publicação científica, com previsão de entrega para o dia 12/07/2019, o Grupo IV da turma B do "ECIAP” buscou, através da materialização do presente artigo, compartilhar suas experimentações vivenciadas.

Por fim, sob análise global, pode-se afirmar que os cenários práticos ofertados pelos estágios são inesgotáveis para a aplicação dos conceitos disseminados em sala de aula e para o alicerce da pesquisa, em suma, fundamentais para o processo formativo dos futuros cirurgiões-dentistas.

\section{Conclusões}

Após análise detalhada dos dispositivos político-pedagógicos atrelados à dinamização do "ECIAP”, através das 
experimentações vivenciadas pelo Grupo IV da Turma B, algumas inferências merecem destaque:

a. A efetividade do instrumento "TPC" no direcionamento dos acadêmicos estagiários no planejamento estratégico de atividades de educação em saúde;

b. O reconhecimento do ambiente escolar como território fértil para o desenvolvimento de ações promotoras de saúde;

c. A importância de se disseminar, em espaços científicos, os aprendizados advindos de experimentações práticas de estágios.

\section{Referências}

1 - Tinti EC. Dilemas entre teoria e prática a partir da formação profissional e das condições objetivas do trabalho cotidiano. In: Capitalismo, trabalho e formação profissional: dilemas do trabalho cotidiano dos assistentes sociais em Ribeirão Preto. São Paulo: Editora UNESP; 2015. p. 97-131.

2 - Albuquerque VS, Gomes AP, Rezende CHA, Sampaio MX, Dias OV, Lugarinho RM. A integração ensino-serviço no contexto dos processos de mudança na formação superior dos profissionais da saúde. Rev Bras Educ Med. 2008; 32(3): 356-362.

3 - Madeira MC. Ensino, Pesquisa, Extensão. In: Carvalho, ACP; Kriger, L (orgs.). Educação Odontológica. São Paulo: Editora Artes Médicas; 2006. p. 97-103.

4 - Almeida LE, Pereira MN, Oliveira V. Governador Valadares (MG) em Extensão: Interfaces para a Dinamização e Instrumentalização do Cenário Extensionista em um Campus Recém-Implantado. Rev Bras Educ Med. 2016; 40(4): 743-750.

5 - Almeida LE. Pró-saúde: ensino, pesquisa e extensão. Juiz de Fora: Editar Editora Associada Ltda; 2009.

6 - Leme PAT, Pereira AC, Menegim MC, Mialhe FL. Perspectivas de graduandos em odontologia acerca das experiências na atenção básica para sua formação em saúde. Ciência \& Saúde Coletiva. 2015; 20(4): 1255-1265.

7 - Bruder MV, Lolli LF, Palácios AR, Rocha NB, Veltrini VC, Gasparetto A, Fujimaki M. Estágio supervisionado na Odontologia: vivência da promoção da saúde e integração multiprofissional. Rev Bras Promoç Saúde. 2017; 30(2): 294-300.

8 - Moimaz SAS, Wakayama B, Garbin AJI, Garbin CAS, Saliba NA. Análise situacional do estágio curricular supervisionado nos cursos de graduação em Odontologia no Brasil: uma questão de interpretação. Revista da ABENO. 2016; 16(4): 19-28. 
9- Creswell JW. Projeto de pesquisa: métodos qualitativo, quantitativo e misto. Porto Alegre: Editora Artmed; 2007.

10 - Bell J. Projeto de pesquisa: guia para pesquisadores iniciantes em educação, saúde e ciências sociais. Porto Alegre: Editora Artmed; 2008.

11 - Minayo MCS. Ciência, técnica e arte: o desafio da pesquisa social. In: Deslandes SF (org.). Pesquisa social: teoria, método e criatividade. Rio de Janeiro: Editora Vozes, 1994. p. 9-29. [acesso 22 de agosto de 2019]. Disponível em http://www.grupodec.net.br/wp-content/uploads/2015/10/ Pesquisa_Social.pdf

12 - Saliba NA, Moimaz AS, Chiaratto RA, Tiano AVP. A utilização da metodologia PBL em Odontologia: descortinando novas possibilidades ao processo ensino-aprendizagem. Rev Odonto Ciênc. 2008; 23(4): 392-396.

13 - Rocha JS, Dias GF, Campanha NH, Baldani MH. O uso da aprendizagem baseada em problemas na Odontologia: uma revisão crítica da literatura. Revista da ABENO. 2016; 16(1): 25-38.

14 - Reul MA, Lima ED, Irineu KN, Lucas RSCC, Costa EMMB, Madruga RCR. Metodologias ativas de ensino aprendizagem na graduação em Odontologia e a contribuição da monitoria: relato de experiência. Revista da ABENO. 2016; 16(2): 62-68.

15 - Lage RH, Almeida SKTT, Vasconcelos GAN, Assaf AV, Robles FRP. Ensino e aprendizagem em odontologia: análise de sujeitos e práticas. Rev Bras Educ Med. 2017; 41(1): 22-29.

16 - Freire P. Extensão ou comunicação? Rio de Janeiro: Editora Paz e Terra; 1983. [acesso em 22 de agosto de 2019]. Disponível em http:// www.emater.tche.br/site/arquivos_pdf/teses/Livro_P_Freire_Extensao_ ou_Comunicacao.pdf>

17 - Freire P. Pedagogia da Autonomia: saberes necessários à pratica educativa. Rio de Janeiro: Paz e Terra; 2006.

18 - Freire P. Educação como Prática da Liberdade. Rio de Janeiro: Paz e Terra; 2007.

19 - Almeida LE, Pereira MN, Bara EF. Projeto de Extensão Sabiá: a introdução de uma prática integralizadora no ensino odontológico. In: Almeida, LE (org.). Pró-saúde: ensino, pesquisa e extensão. Juiz de Fora: Editar Editora Associada Ltda; 2009. p. 126-164.

20 - Nóbrega MM, Lopes Neto D, Santos SR. Uso da técnica de brainstorming para tomada de decisões na equipe de enfermagem de saúde pública. R Bras Enferm. 1997; 50(2): 247-256.

21 - Braia F, Curral L, Gomes C. Criatividade em contexto organizacional: o impacto de recompensas extrínsecas e do feedback negativo no desempenho criativo. Revista Psicologia. 2014; 28(2): 45-62.

22 - Carabetta Júnior V. A Utilização de Mapas Conceituais como Recurso Didático para a Construção e Interrelação de Conceitos. Rev Bras Educ Med. 2013; 37(3): 441-447. 
23 - Tavares R. Construindo mapas conceituais. Ciências \& Cognição. 2007; 12(-): 72-85

24 - Almeida LE, Oliveira Júnior GI. Sistema de Execução do Projeto. In: Almeida, LE (org.). Pró-Saúde: Ensino, Pesquisa e Extensão. Juiz de Fora: Editar Editora Associada Ltda; 2009. p. 63-86.

25 - Rossetti H. Saúde para a Odontologia. São Paulo: Editora Santos; 1999. 


\title{
Trainee academics in a school environment: policy-pedagogical analysis of experiments
}

\begin{abstract}
Objective: To analyze the political-pedagogical significance of experiences experienced by trainees of a dentistry course in a school environment. Material and Method: Qualitative study transversally structured under narrative-descriptive strategy and molded to the argumentative technique. Results: The "Clerkship of Integrated Clinic in Primary Care" was didactically systematized in two periods, "Pre-intervention" and "Intervention". From the first, two actions were unveiled: the "Contextualization of the Interns" and the "Structuring, Environmentalization and Survey of Work Environment Needs". The second was guided by the pedagogical logic of the "TPC" (Theorize-Practice-Criticize) instrument, where all programmed actions followed the active logic of strategic planning, contextualized to the realities of the practice scenario (school environment). Conclusion: From the experiments experienced some inferences stood out: the effectiveness of the "TPC" instrument in guiding the trainee academics in the strategic planning of health education actions; the recognition of the school environment as fertile territory for the development of health promoting activities; the importance of disseminating, in scientific spaces, the learning that comes from practical experimentation of internships.
\end{abstract}

KEYWORDS: Health promotion. Health education. Clinical clerkship. Community-institutional relations. Strategic planning.

\section{Como citar este artigo}

Almeida LE, Pereira MN, Carmo VCFT, Mendonça BPN, Bonato LL, Maurício NV, Fuhrmann MFL, Sequeto MPF, Medina NSP, Caniato PER, Tavares RN. Estagiários em um ambiente escolar: análise político-pedagógica das experimentações vivenciadas. Rev Odontol Bras Central 2021; 30(89): 97-115. DOI: 10.36065/robrac.v30i89.1351 